\title{
Postoperative chemoradiotherapy is superior to postoperative chemotherapy alone in squamous cell lung cancer patients with limited N2 lymph node metastasis
}

\author{
Liyu Su ${ }^{1,2,3+}$, Mingqiu Chen ${ }^{1,4+}$, Huiyan Su${ }^{5}$, Yaqing Dai ${ }^{6}$, Shaoxing Chen ${ }^{7}$ and Jiancheng $\mathrm{Li}^{1^{*}}$
}

\begin{abstract}
Background: The aim of the present study was to assess the efficacy of postoperative chemoradiotherapy (POCRT) following surgery in non-small-cell lung cancer patients with N2 lymph node metastasis (N2-NSCLC).

Methods: The clinical data of patients with N2-NSCLC treated with POCRT or postoperative chemotherapy (pCT) alone were retrospectively collected and reviewed. The overall survival (OS) rates were analyzed utilizing the Kaplan-Meier method and compared by the log-rank test. Cox regression analysis was used to determine factors significantly associated with survival. Propensity score matching (PSM) analysis was used to compensate for differences in baseline characteristics and OS was compared after matching.

Results: Between 2004 and 2014, a total of 175 patients fulfilled the inclusion criteria, 60 of whom were treated with POCRT, while 115 were administered $p C T$. The 1, 3 and 5-year OS rates in the POCRT and $p C T$ groups were 98.3 vs. $86.1 \%, 71.7$ vs. $53.0 \%$ and 45.7 vs. $39.0 \%$, respectively $(P=0.019)$. Compared with $\mathrm{pCT}$, POCRT improved OS in patients with squamous cell subtype $(P=0.010)$, no lymphovascular invasion $(P=0.006)$, pN2a $(P=0.006)$ or total number of metastatic lymph nodes $\leq 7(P=0.016)$. After PSM, these survival differences between POCRT and $\mathrm{PCT}$ remained significant in patients with squamous cell lung cancer $(P=0.010)$.
\end{abstract}

Conclusions: POCRT following complete resection may be beneficial for patients with squamous cell lung cancer, particularly those with limited nodal involvement.

Keywords: N2 lymph node metastasis, Non-small-cell lung cancer, Postoperative chemoradiotherapy, Survival

\section{Background}

Lung cancer remains the most common type of cancer and the leading cause of cancer-related mortality worldwide, with 1.8 million deaths predicted and 2.1 million new lung cancer cases in 2018 [1] and an increasing estimated cancer incidence, expected to reach three million by 2035 [2]. World Health Organization (WHO) divides lung cancer into small-cell lung cancer (SCLC)

\footnotetext{
* Correspondence: jianchengli_jack@126.com

† Liyu Su and Mingqiu Chen contributed equally to this work.

${ }^{1}$ Department of Radiation Oncology, Fujian Cancer Hospital \& Fujian Medical

University Cancer Hospital, Fuzhou 350014, Fujian, China

Full list of author information is available at the end of the article
}

and non-small-cell lung cancer (NSCLC) [3]. NSCLC accounts for $>80 \%$ of all lung cancer cases and it includes two major pathological subtypes: Squamous cell (epidermoid) carcinoma and non-squamous cell carcinoma (including adenocarcinoma, large-cell carcinoma and other subtypes) [4].

Surgical resection is currently the mainstay of definitive treatment for localized NSCLC. In addition, postoperative chemotherapy $(\mathrm{pCT})$ is considered as the standard postoperative treatment for NSCLC patients with metastases to the lymph nodes [5]. However, even when administered with bimodal treatment (BMT, surgery and $\mathrm{pCT}$ ) strategies, the prognosis of patients with metastatic

(c) The Author(s). 2019 Open Access This article is distributed under the terms of the Creative Commons Attribution 4.0 International License (http://creativecommons.org/licenses/by/4.0/), which permits unrestricted use, distribution, and 
lymph nodes (MLN) remains dismal $(<25 \%$ at 5 years) [6], which is mainly due to a high (up to $30 \%$ ) local tumor failure rate as the first site of recurrence [7]. Thus, it has come to be considered that postoperative radiotherapy (PORT) should be added to BMT to improve local control and survival, although this may not be the case, as several clinical trials confirmed that POCRT did not improve the survival of patients with N1 stage disease after complete (R0) resection [8]. Particularly for patients with metastases to the ipsilateral mediastinal lymph nodes (N2-NSCLC), the role of PORT following BMT remains controversial due to its variable response rates and effectiveness [9].

In the present study, the clinical data of patients with N2-NSCLC treated with POCRT or pCT following surgery were retrospectively collected and analyzed to explore the status of POCRT in N2-NSCLC.

\section{Methods}

\section{Patient selection criteria}

This retrospective study was approved by Fujian Province Cancer Hospital Institutional Review Board (No. KT2018-015-01). All patients provided written informed consent prior to treatment, and all information was anonymized prior to analysis.

The eligibility and exclusion criteria for the present retrospective study were as follows: Primary histologically proven NSCLC, good performance status (Eastern Cooperative Oncology Group performance status score (ECOG PS) $\leq 2$ ), complete pretreatment workup and follow-up data, and without other concomitant medical conditions that required treatment, initially treated with curative surgery followed by chemotherapy or radiotherapy, pathological stage TanyN2M0 (pTanyN2M0). Patients who survived $<1$ month after surgery were considered as surgical fatalities and were excluded from the present study.

The pTNM stage was re-determined according to the 8th American Joint Committee on Cancer TNM staging system [10] based on the data of the surgical pathology specimen. N2 was subclassified into $\mathrm{N} 2$ at a single station without N1 involvement ('skip' metastasis, N2a1), $\mathrm{N} 2$ at a single station with N1 involvement (N2a2), and $\mathrm{N} 2$ at multiple stations (N2b) [11].

\section{Treatment}

All enrolled patients were initially treated with thoracotomy, including wedge or sleeve resection, lobectomy and pneumonectomy, by minimally invasive or conventional surgery. The initiation of $\mathrm{pCT}$ started no later than 2 weeks after the operation. The regimens of $\mathrm{pCT}$ in the present study included a two-drug combination chemotherapy regimen based on cisplatin and were administered for at least 2 cycles of full-dose chemotherapy. Chemotherapy regimen includes NP (vinorelbine $25 \mathrm{mg} / \mathrm{m}^{2} \mathrm{dl}, \mathrm{d} 8+$ cisplatin $25 \mathrm{mg} / \mathrm{m}^{2} \mathrm{dl}-3$ ), GP (gemcitabine $1250 \mathrm{mg} / \mathrm{m}^{2} \mathrm{dl}$, $\mathrm{d} 8+$ cisplatin $25 \mathrm{mg} / \mathrm{m}^{2} \mathrm{dl}-3$ ), TP (paclitaxel $135 \mathrm{mg} / \mathrm{m}^{2}$ $\mathrm{d} 1+$ Cisplatin $25 \mathrm{mg} / \mathrm{m}^{2} \mathrm{dl}-3$ ), DP (docetaxel $75 \mathrm{mg} / \mathrm{m}^{2} \mathrm{dl}+$ cisplatin $25 \mathrm{mg} / \mathrm{m}^{2} \mathrm{dl}-3$ ), PC (pemetrexed $500 \mathrm{mg} / \mathrm{m}^{2} \mathrm{dl}+$ cisplatin $25 \mathrm{mg} / \mathrm{m}^{2} \mathrm{dl}-3$,only for non-squamous cell carcinoma), 21-28d/cycle. Carboplatin was alternatively used in case of intolerance to cisplatin. Adjustments to the $\mathrm{pCT}$ time intervals and dose intensities were similar to our previous study [12].

POCRT was executed sequentially or sandwiched with pCT with three-dimensional conformal or intensitymodulated radiotherapy technique. The targets, including clinical target volume (CTV), planned target volume (PTV) and organs at risk (OARs) of radiotherapy. The CTV should include the bronchial stump and the highrisk lymphatic drainage area. The PTV was defined as the CTV plus a 0.5 or $0.6 \mathrm{~cm}$ margin for setup uncertainty and respiratory motion. The prescribed dose is defined as the dose received by 95\% PTV. Dose limitation for organ-at-risk was defined: lungs V20 $\leq 25 \%$, lungs V5 $<60 \%$, unilateral lung V $20 \leq 45 \%$. Heart $\mathrm{V} 30<40 \%$, V $40<30 \%$, mean dose $\leq 30 \mathrm{~Gy}$, esophagus $\mathrm{V} 50<50 \%$, and $<45 \mathrm{~Gy}$ for maximum spinal cord dose. The target dose and the dose limitations of OARs were defined and adjusted as described in our previous study [12]. The median dose to CTV was 5000 (range 4400-6000) cGy, with 180-200 cGy per fraction.

\section{Surveillance and statistical analysis}

The follow-up schedule for patients was as previously reported [12]. In brief, patients were evaluated every 3 months for the first 2 years after surgery, every 6 months for the next 3 years, and once annually thereafter. All patient outcomes were evaluated in April 2018. The primary endpoint was OS. The OS was calculated from the date of diagnosis to the date of death, or the date of the last follow-up.

Data were analyzed using SPSS version 24.0 (IBM Corp., Armonk, NY, USA). Survival curves were produced using the Kaplan-Meier estimator method and compared with the log-rank test. Univariable and multivariable analyses of clinical characteristics, including sex, age, tumor location, $\mathrm{pT}$ stage, $\mathrm{pN} 2$ subclass, total number of MLNs, histopathological type, lymphovascular invasion, radiotherapy dose of CTV, regimens and cycles of $\mathrm{pCT}$ and surgical modality, associated with OS, were performed using the Cox proportional hazards model. Confidence intervals (CIs) represented 95\% lower and upper limits.

Propensity score matching (PSM) analyses were used to compensate for differences in baseline characteristics between the POCRT and $\mathrm{pCT}$ groups to confirm the survival difference. First, all available patient and tumor variables were compared using the $x^{2}$ test. Next, a propensity score was calculated using a logistic regression with the 
imbalanced variables that were statistically significantly correlated with OS on multivariate analysis. Finally, all analyses regarding OS were adjusted based on the generated propensity score [13]. Pearson's $x^{2}$ test was subsequently performed to compare the differences between the POCRT and pCT groups after matching.

\section{Results}

\section{Patient characteristics}

Between September 2004 and December 2014, a total of 3262 surgically treated patients with NSCLC were reviewed.
A total of 175 patients fulfilled the inclusion criteria, of whom 115 patients were administered $\mathrm{pCT}$ and 60 patients received POCRT. No significant differences in clinical characteristics were identified between the two groups, with the exception of surgical modality and total number of chemotherapy cycles (Table 1), which did not affect patient survival in the subsequent multivariate analyses.

\section{Survival analysis in the entire cohort}

At the last follow-up, 57 patients remained alive and 118 patients had died, of whom 87 patients had succumbed

Table 1 Clinical characteristics of patients before and after matching

\begin{tabular}{|c|c|c|c|c|c|c|}
\hline \multirow[t]{2}{*}{ Characteristics } & \multicolumn{3}{|l|}{ Pre-matched } & \multicolumn{3}{|l|}{ Matched } \\
\hline & $\overline{\text { POCRT }}$ & $\mathrm{pCT}$ & $p$ & POCRT & $\mathrm{pCT}$ & $p$ \\
\hline Gender & & & 0.523 & & & 0.385 \\
\hline Male & 42 & 75 & & 42 & 33 & \\
\hline Female & 18 & 40 & & 18 & 20 & \\
\hline Median age (y, range) & $58(37-74)$ & $56(33-75)$ & 0.222 & $58(37-74)$ & $57(41-73)$ & 0.217 \\
\hline ECOG scoring & & & 0.572 & & & 0.149 \\
\hline 0 & 18 & 36 & & 18 & 21 & \\
\hline 1 & 42 & 77 & & 42 & 30 & \\
\hline 2 & 0 & 2 & & 0 & 2 & \\
\hline Position & & & 0.636 & & & 0.190 \\
\hline Central & 30 & 62 & & 30 & 20 & \\
\hline Periphery & 30 & 53 & & 30 & 33 & \\
\hline \multicolumn{7}{|l|}{ Vessel invasion } \\
\hline Positive & 16 & 28 & 0.737 & 16 & 15 & 0.846 \\
\hline Negative & 44 & 87 & & 44 & 38 & \\
\hline pT stage & & & 0.099 & & & 0.067 \\
\hline 1 & 13 & 16 & & 13 & 16 & \\
\hline 2 & 35 & 58 & & 35 & 35 & \\
\hline 3 & 8 & 19 & & 8 & 1 & \\
\hline 4 & 4 & 22 & & 4 & 1 & \\
\hline Operation modality & & & 0.044 & & & 0.674 \\
\hline Wedge or Sleeve & 4 & 2 & & 4 & 2 & \\
\hline Lobectomy & 54 & 99 & & 54 & 48 & \\
\hline Pneumonectomy & 2 & 14 & & 2 & 3 & \\
\hline Pathology & & & 0.582 & & & 0.261 \\
\hline SCC & 18 & 30 & & 18 & 11 & \\
\hline Non-SCC & 42 & 85 & & 42 & 42 & \\
\hline pN stage & & & 0.924 & & & 0.646 \\
\hline N2a1 & 13 & 26 & & 13 & 9 & \\
\hline N2a2 & 18 & 37 & & 18 & 20 & \\
\hline $\mathrm{N} 2 \mathrm{~b}$ & 29 & 52 & & 29 & 24 & \\
\hline Chemotherapy cycles (range) & $4(2-6)$ & $3(2-6)$ & 0.0001 & $4(2-6)$ & $4(2-6)$ & 0.143 \\
\hline Total number of MLNs (range) & $4(1-28)$ & $4(1-26)$ & 0.536 & $4(1-28)$ & $4(1-23)$ & 0.333 \\
\hline CTV dose (range) & $5000(4400-6000)$ & - & & $5000(4400-6000)$ & - & \\
\hline
\end{tabular}


to the disease (10 to locoregional recurrence, 34 to distant metastasis and 43 to both) and 31 patients had died from unknown causes (Table 2).

The median follow-up time in the entire cohort and in the surviving patients was $48(6-128)$ and 68 (38-128) months, respectively. The 1,3 and 5-year OS rates for the entire cohort were $90.3,60.0$ and $41.2 \%$, respectively. The 1, 3 and 5-year OS rates in the POCRT and pCT groups were 98.3 vs. $86.1 \%, 71.7$ vs.53.0\% and 45.7 vs. $39.0 \%$, respectively $(P=0.019)$ (Fig. 1a, Table 2 ).

Univariate and multivariate analyses indicated that $\mathrm{T}$ stage, total number of MLNs and POCRT were independent factors affecting OS (Table 3). The ROC curve of the total number of MLNs was applied to identify the cut-off number that was most significantly correlated with patient survival using the area under the curve (AUC) (Fig. 2a), indicating that patients with $>7$ MLNs had a significantly inferior survival compared with patients with $\leq 7$ MLNs $(P=0.0001)$ (Fig. 2b).

\section{Survival analysis between POCRT and $\mathrm{PCT}$ in various subgroups}

To identify patients who may benefit from POCRT, exploratory subgroup analyses were conducted among various patient subgroups, particularly of the abovementioned significant independent prognostic factors. The results demonstrated that, compared with the corresponding subgroups, POCRT benefited patients with squamous cell histology, without lymphovascular invasion, $\leq 7$ MLNs or N2a (Fig. 3a, c, e and g). Although the survival of patients with $\mathrm{T} 4$ stage also differed between POCRT and $\mathrm{PCT}$, the conclusion was not robust, as the number of patients with $\mathrm{T} 4$ in the present study was limited.

To balance the bias due to the retrospective nature of this study, PSM based on the clinical baseline characteristics, including age, gender, surgical modality, pathology, lymphovascular invasion, $\mathrm{pT}$ stage, $\mathrm{pN}$ stage, total number of MLNs, regimens and cycles of chemotherapy, was conducted. Following PSM, a total of 113 events

Table 2 Failure Pattern and survival

\begin{tabular}{lllll}
\hline & POCRT & pCT & Total & $\mathrm{p}$ \\
\hline Pattern of failure, $\mathrm{n}(\%)$ & & & & 0.047 \\
Locoregional alone & 2 & 8 & 10 & \\
Locoregional and distant & 13 & 30 & 43 & \\
Distant alone & 16 & 18 & 34 & \\
unknown & 5 & 26 & 31 & \\
OS rates (\%) & & & & 0.019 \\
1- year & 98.3 & 86.1 & 90.3 & \\
3- year & 71.7 & 53.0 & 60.0 & \\
5- year & 45.7 & 39.0 & 41.2 & \\
\hline
\end{tabular}

were identified in both the POCRT and pCT groups, with 60 and 53 patients in each group, respectively. Following PSM, the 1, 3 and 5-year OS rates in the POCRT and pCT groups were 98.3 vs. $88.7 \%, 71.7$ vs. $62.3 \%$ and 45.7 vs. $50.7 \%$, respectively $(P=0.463)$ (Fig. $1 \mathrm{~b})$. And the survival differences between POCRT and $\mathrm{pCT}$ in the various subgroups were not statistically significant, except in patients with squamous cell lung cancer (Fig. 3b, d, f and h).

\section{Discussion}

Even with the development of molecular targeted treatment for NSCLC, pCT remains the standard postoperative adjuvant treatment for NSCLC patients with MLNs [5], whereas the additive effects of delivering radiotherapy (RT) to MLN-NSCLC patients treated with BMT have not been established [9]. Burdett et al. conducted a metaanalysis of randomized trials and demonstrated that, compared with $\mathrm{pCT}$ alone, POCRT failed to confer a survival benefit in NSCLC patients with either NO, N1 or N2 disease [14]. However, the greatest limitation of Burdett's report was that patients enrolled in that study were treated with outdated radiation equipment and techniques, which ultimately contributed to a negative outcome as a result of RT-related cardiac and pulmonary toxicity [5]. Multiple subsequent studies have been conducted to explore the role of POCRT with contemporary RT techniques in resectable NSCLC. Unfortunately, the results demonstrated that even POCRT using modern technology did not confer a survival benefit to patients with NSCLC, but instead increased the relative risk of death [8].

However, contrary to abovementioned studies, Lally et al. conducted a landmark meta-analysis using the Surveillance, Epidemiology and End Results Database and reported that, despite the fact that survival was not increased in patients with N0 and N1 disease, N2-NSCLC patients achieved a notable OS improvement from POCRT with modern technology [15]. Then, several comparable studies confirmed the advantage of POCRT in N2-NSCLC [16]. Similarly, in the present retrospective study, compared with pCT, POCRT achieved a significant survival benefit in N2-NSCLC patients. To make our conclusion more robust, PSM was conducted to compensate the selection bias of the present retrospective study. Following PSM, POCRT still clearly demonstrated superior survival compared with $\mathrm{pCT}$, indicating that POCRT should be considered for patients with N2-NSCLC, despite the fact that no randomized clinical trials have been conducted to validate it thus far [17].

Due to the heterogeneous nature of N2-NSCLC, some studies proposed that POCRT should only be considered for a certain N2 subgroup rather than for all N2-NSCLC patients [9]; however, the criteria for classifying N2 disease into subcategories had not been established. 

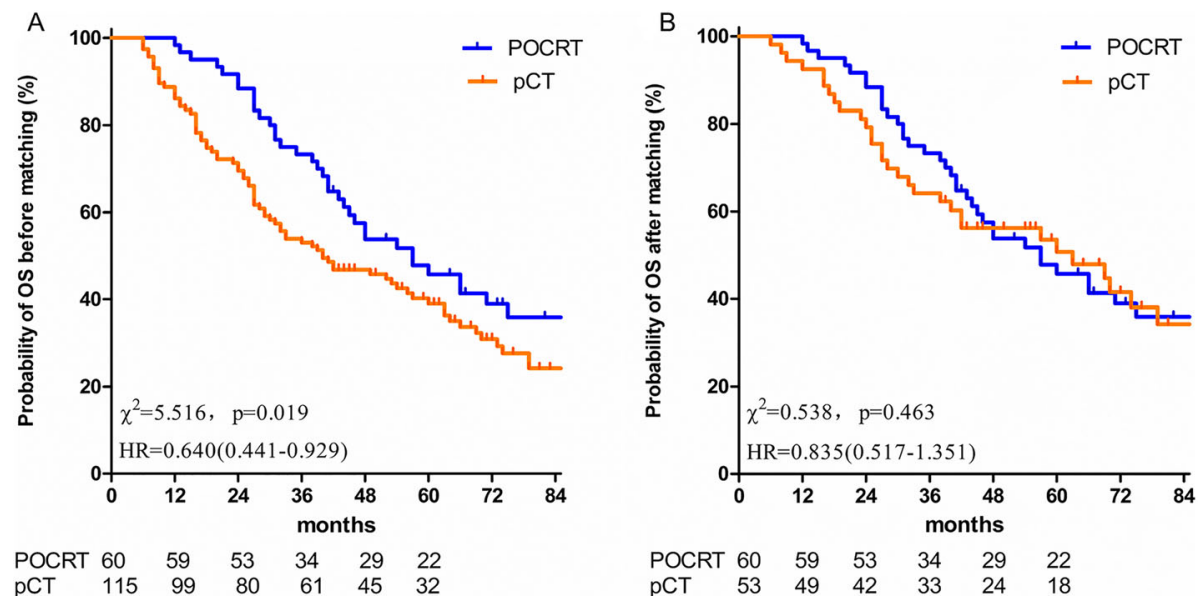

Fig. 1 Comparison of OS between PCT alone and POCRT before and after matching. a. Comparison of OS between pCT alone and POCRT before matching. b. Comparison of OS between $\mathrm{PCT}$ alone and POCRT after matching. OS, overall survival; $\mathrm{PCT}$, postoperative chemotherapy; POCRT, postoperative chemoradiotherapy

Asamura et al. proposed staging N2 into pN2a1, pN2a2 and $\mathrm{pN} 2 \mathrm{~b}$ subgroups based on the combination of MLN location, number and absence versus presence of skip metastases [11], which had been reported to estimate a more accurate prognosis in N2-NSCLC. To identify which N2 subgroup would benefit from POCRT, a stratified analysis based on Asamura's N2 staging system performed in the present study indicated that, compared with $\mathrm{pCT}$, patients with $\mathrm{N} 2 \mathrm{a}$ (whether N2a1 or N2a2) treated with POCRT achieved a significantly better survival.

Considering that the total number of MLNs represented a strong independent prognostic factor in NSCLC [18], a stratified analysis according to the total number of MLNs was conducted to determine which patient subgroup would benefit from POCRT in the present study. The results demonstrated that patients with $\leq 7$ MLNs, contrary to those with $>7$ MLNs, gained a significant survival benefit from POCRT compared with pCT.

It is well-known that lymphovascular invasion, which forebodes a high risk of nodal metastasis, is an independent factor affecting survival in early-stage NSCLC patients [19-21]. However, contrary to its prominent role in early-stage lung cancer, lymphovascular invasion was not found to be significantly correlated with survival in the present study. This finding indicated that, in advanced N2-NSCLC, the effect of lymphovascular invasion on survival may be offset by the effect of N2. In addition, the stratified analysis demonstrated that, compared with

Table 3 Prognostic factors by univariate and multivariate analysis

\begin{tabular}{llll}
\hline Prognostic factors & Univariate & & Multivariable \\
\cline { 2 - 3 } & $\mathrm{p}$ & $\mathrm{HR}(95.0 \% \mathrm{Cl})$ & $\mathrm{P}(95.0 \% \mathrm{Cl})$ \\
\hline Gender & 0.135 & $1.014(0.991-1.037)$ & \\
Age & 0.245 & $0.736(0.492-1.100)$ & \\
ECOG & 0.214 & $1.269(0.872-1.848)$ & \\
Tumor location & 0.110 & $0.742(0.514-1.070)$ & 0.024 \\
Operation modality & 0.006 & $2.040(1.230-3.382)$ & \\
Pathology type & 0.912 & $1.023(0.686-1.525)$ & 0.0001 \\
pT stage & 0.011 & $1.287(1.059-1.565)$ & $1.264(1.031-1.550)$ \\
pN stage & 0.929 & $1.011(0.798-1.280)$ & \\
Total number of MLNs & 0.0001 & $1.085(1.047-1.124)$ & $1.090(1.053-1.130)$ \\
Vessel invasion & 0.821 & $0.951(0.617-1.467)$ & 0.012 \\
Total Chemotherapy cycles & 0.019 & $0.797(0.659-0.964)$ & $0.601(0.403-0.895)$ \\
POCRT & 0.021 & $0.628(0.423-0.932)$ & \\
\hline
\end{tabular}



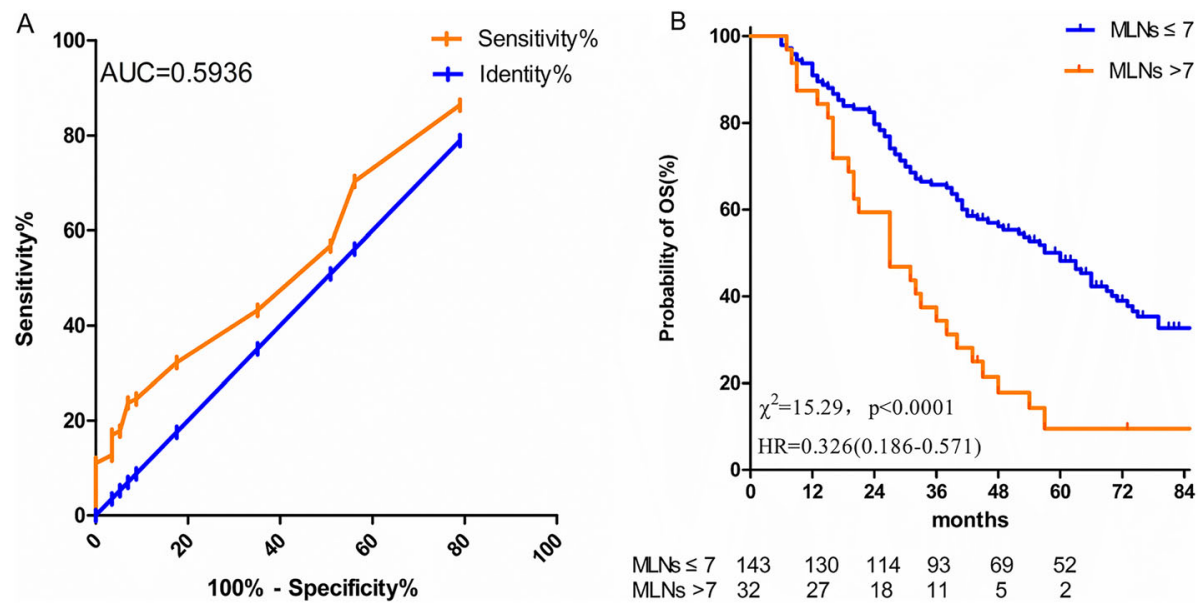

Fig. 2 a.The ROC curve of the cut-off number of MLNs. b. Comparison of OS between $\leq 7 \mathrm{MLNS}$ and $>7 \mathrm{MLNs}$

pCT, patients without lymphovascular invasion gained a more prominent survival benefit from POCRT.

Taken together, the abovementioned results lead to the conclusion that POCRT may improve the survival of N2-NSCLC patients with limited nodal involvement. An explanation of the results may be that patients with more extensive nodal spread had a high frequency of distant metastases [22] and the local control achieved with POCRT cannot be translated into long-term survival.

Although surgery is indicated in selected T4N0-1 patients, the efficacy of surgery in patients with T4 N2
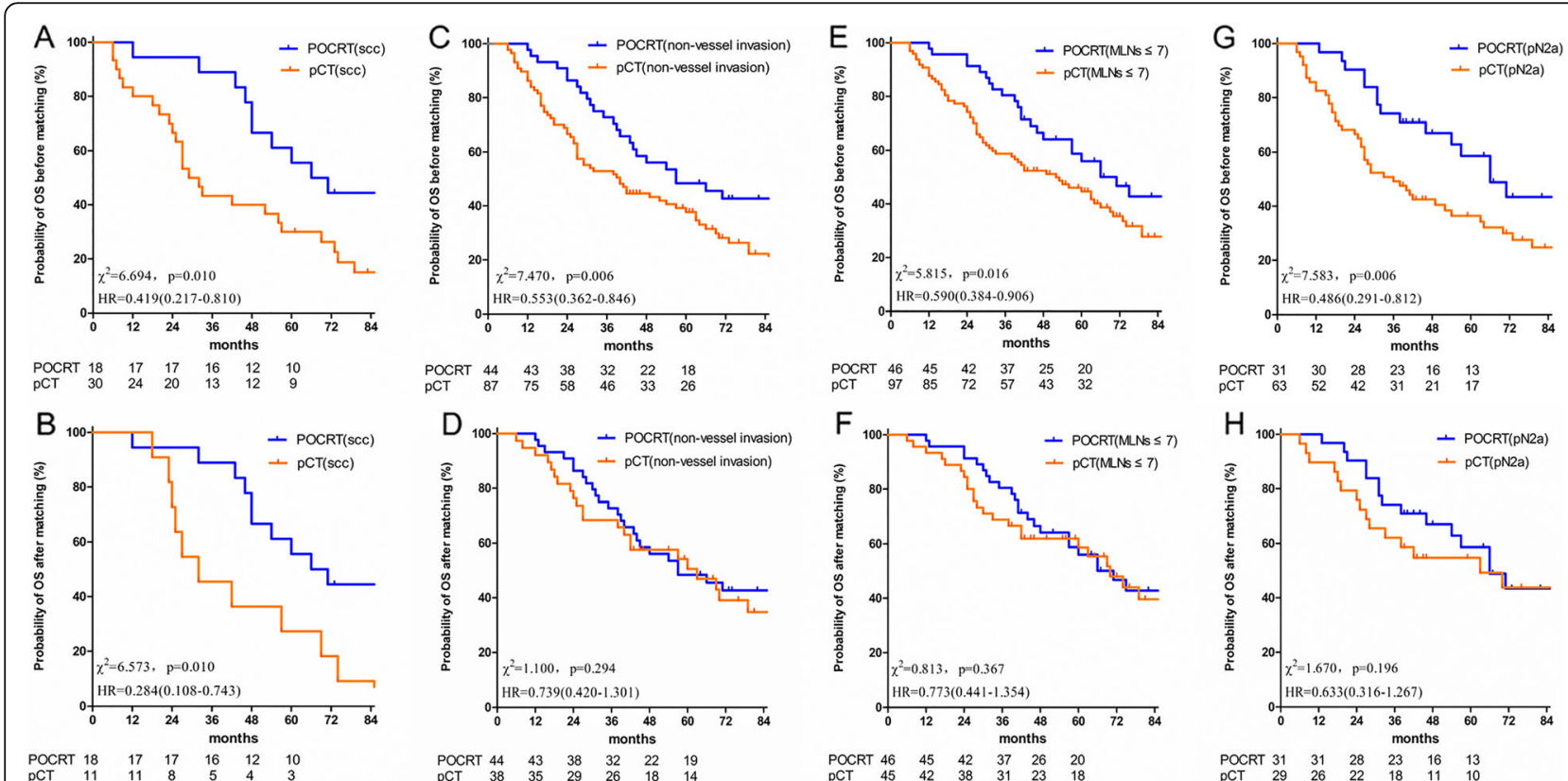

$\begin{array}{lllllll}\text { POCRT } & 18 & 17 & 17 & 16 & 12 & 10 \\ \text { pCT } & 11 & 11 & 8 & 5 & 4 & 3\end{array}$

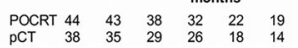

$\begin{array}{lllllll}\text { POCRT } & 46 & 45 & 42 & 37 & 26 & 20 \\ \text { pCT } & 45 & 42 & 38 & 31 & 23 & 18\end{array}$

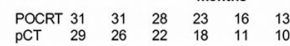

Fig. 3 OS in various subgroups of independent significant factors. OS, overall survival. a. Comparison of OS between pCT alone and POCRT in patients with squamous cell carcinoma before matching. b. Comparison of OS between pCT alone and POCRT in patients with squamous cell carcinoma after matching. c. Comparison of OS between pCT alone and POCRT in patients with without lymphovascular invasion before matching. $\mathbf{d}$. Comparison of OS between PCT alone and POCRT in patients with without lymphovascular invasion after matching. e. Comparison of OS between pCT alone and POCRT in patients with $\leq 7 \mathrm{MLNs}$ before matching. f. Comparison of OS between pCT alone and POCRT in patients with $\leq 7$ MLNs after matching. g. Comparison of OS between pCT alone and POCRT in patients with pN2a before matching. $\mathbf{h}$. Comparison of OS between pCT alone and POCRT in patients with pN2a after matching. OS, overall survival; pCT, postoperative chemotherapy; POCRT, postoperative chemoradiotherapy; scc, squamous cell carcinoma; non-vessel invasion, without lymphovascular invasion; MLNs $\leq 7$, metastatic lymph nodes $\leq 7$; pN2a, Combine pN2a1 and pN2a2, N2 at a single station without N1 involvement ('skip' metastasis, N2a1), N2 at a single station with $\mathrm{N} 1$ involvement (N2a2) 
disease has not been convincing [23]. Patel et al. recommended that only $\mathrm{T} 4 \mathrm{~N} 2$ patients with good performance status and minimal N2 nodal involvement (single-station, microscopic) should be considered for surgery [24]. However, as patients with T4 and minimal N2 are rare, the benefit of POCRT for T4 N2 patients had not been previously reported. The present study demonstrated that patients with T4 stage had a significantly inferior survival compared with stage T1, T2 and T3. However, the conclusion was not convinced owing to the sample of patients with $\mathrm{T} 4$ disease was too small in the current study.

Previous studies demonstrated that central tumor location is associated with a higher rate of surgical resection margin positivity compared with peripheral tumor location, and such patients may benefit from POCRT [25]. However, to the best of our knowledge, there is no study on POCRT for patients with centrally located tumor undergoing R0 resection. The present study indicated that survival did not differ significantly between central and peripheral tumor location, whether in the entire cohort or in the PSM matched cases. Therefore, tumor location was not found to be a risk factor for N2-NSCLC and should not considered an indicator for POCRT.

The management of lung adenocarcinoma had dramatically changed over the past decade with the introduction of targeted therapeutic agents for genotypical selection [26, 27]. By contrast, progress in squamous cell lung cancer treatment has been modest, and there has yet to be a successful application of targeted therapy in this disease [28]; therefore, patients with squamous cell lung cancer have been receiving the same conventional treatment for the last decade. In the present study, patients with squamous cell lung cancer achieved a notable survival benefit from POCRT, whether in the entire cohort or in the matched cases.

Therefore, POCRT may be specifically recommended to N2 patients with squamous cell lung cancer due to the current lack of effective targeted therapies. However, as the present study is the first to demonstrate that POCRT confers a survival benefit in squamous cell lung cancer based on a limited patient sample, this recommendation should be interpreted with caution as it requires validation by further clinical trials.

\section{Conclusions}

POCRT following complete resection may be beneficial for patients with squamous cell lung cancer, particularly those with limited $\mathrm{N}$ involvement. Due to the limitations of the present study, including the retrospective design with inherent biases, the small sample enrolled, the lack of unified chemotherapy regimens and the assessment of OS alone, the results of our investigation must be interpreted with caution.

\section{Supplementary information}

Supplementary information accompanies this paper at https://doi.org/10. 1186/s12885-019-6141-z.

Additional file 1. Associated Data.The file included the data of the treatment of 175 NSCLC patients. The treatment group was divided into 2 subgroups( 0 for $\mathrm{pCT}$ and 1 for POCRT).The gender, age, ECOG scoring ,tumor position, Vessel invasion, T stage, Operation modality, Pathology, pN stage, Chemotherapy cycles, Total number of MLNs and CTV dose were divided into different subgroups according to the details list in the Table 1. The OS was calculated from the date of diagnosis to the date of death, or the date of the last follow-up. The survival group was divided into 2 subgroups (0 for survival and 1 for death). (XLSX 35 kb)

\section{Abbreviations}

AUC: Area under the curve; BMT: Bimodal treatment; Cls: Confidence intervals; CTV: Clinical target volume; ECOG PS: Eastern Cooperative Oncology Group performance status score; MLNs: Metastatic lymph nodes; N2-NSCLC: Non-small-cell lung cancer patients with N2 lymph node metastasis; NSCLC: Non-small-cell lung cancer; OARs: Organs at risk;

OS: Overall survival; pCT: Postoperative chemotherapy; POCRT: Postoperative chemoradiotherapy; PORT: Postoperative radiotherapy; PSM: Propensity score matching; PTV: Planned target volume; RT: Radiotherapy; SCLC: Small-cell lung cancer; WHO: World Health Organization

\section{Acknowledgments}

The authors thank all patients who participated in the present study.

\section{Authors' contributions}

$J \mathrm{~L}, \mathrm{LS}$ and MC participated in the design of the study, carried out the clinical data analysis and drafted the manuscript; HS, YD and SC participated in the data collection; LS and MC contribute with the clinical data analysis and involved in revising the manuscript; All authors read and approved the final manuscript.

\section{Funding}

This study was supported in part by grants from the Fujian Provincial Health \& Family Planning Commission (Project Number: 2016-ZQN-13, 2016-ZQN32), the Fujian Provincial Department of Science \& Technology (Project Number: 2017Y9079), the Fujian Provincial Platform for Medical Laboratory Research and Key Laboratory for Tumor Individualized Active Immunity (Project Number: FYKFKT-2017015) and the Science and Technology Program of Fujian Province (Project Number: 2018Y2003) in the design of the study and analysis, interpretation of data and in writing the manuscript.

\section{Availability of data and materials}

The data used to support the findings of this study are included with the article and Additional file 1.

\section{Ethics approval and consent to participate}

This retrospective study was approved by Fujian Province Cancer Hospital Institutional Review Board (No. KT-2018-015-01). All patients provided written informed consent prior to treatment, and all information was anonymized prior to analysis.

\section{Consent for publication}

Not applicable.

\section{Competing interests}

The authors declare the submitted work was not carried out in the presence of any personal, professional or financial relationships that could potentially be construed as a conflict of interest.

\section{Author details}

${ }^{1}$ Department of Radiation Oncology, Fujian Cancer Hospital \& Fujian Medical University Cancer Hospital, Fuzhou 350014, Fujian, China. ${ }^{2}$ Fujian Medical University, Fujian 350122, China. ${ }^{3}$ Department of Oncology, Fujian Cancer Hospital \& Fujian Medical University Cancer Hospital, Fuzhou 350014, Fujian, China. ${ }^{4}$ Fujian Provincial Platform for Medical Laboratory Research of First Affiliated Hospital, Fujian, China. ${ }^{5}$ Department of Radiation Oncology, Fujian 
Children's Hospital, Fujian, China. ${ }^{6}$ Department of Radiation Oncology, The First Affiliated Hospital of Xiamen University, Fujian, China. ${ }^{7}$ Department of Radiation Oncology, The 175th Hospital of PLA (The Chinese People's Liberation Army), Fujian, China.

\section{Received: 7 March 2019 Accepted: 6 September 2019}

Published online: 30 October 2019

\section{References}

1. Bray F, Ferlay J, Soerjomataram I, Siegel RL, Torre LA, Jemal A. Global Cancer statistics 2018: GLOBOCAN estimates of incidence and mortality worldwide for 36 cancers in 185 countries. CA Cancer J Clin. 2018;68:394-424.

2. Didkowska J, Wojciechowska U, Manczuk M, Lobaszewski J. Lung cancer epidemiology: contemporary and future challenges worldwide. Ann Transl Med. 2016:4:150.

3. Travis WD, Brambilla E, Nicholson AG, Yatabe Y, Austin JHM, Beasley MB, Chirieac LR, Dacic S, Duhig E, Flieder DB, Geisinger K, Hirsch FR, Ishikawa Y, Kerr KM, Noguchi M, Pelosi G, Powell CA, Tsao MS, Wistuba I, Panel WHO. The 2015 World Health Organization classification of lung tumors: impact of genetic, clinical and radiologic advances since the 2004 classification. J Thorac Oncol. 2015;10:1243-60.

4. Howlader N, Noone A, Krapcho M. SEER Cancer Statistics Review, 1975-2014. Bethesda, MD: National Cancer Institute; 2017. Based on November 2016 SEER data submission, posted to the SEER web site. https://seer.cancer.gov/ archive/csr/1975_201

5. Robinson CG, Patel AP, Bradley JD, DeWees T, Waqar SN, Morgensztern D, Baggstrom MQ, Govindan R, Bell JM, Guthrie TJ. Postoperative radiotherapy for pathologic N2 non-small-cell lung cancer treated with adjuvant chemotherapy: A review of the National Cancer Data Base. J Clin Oncol. 2015:33:870.

6. Vansteenkiste JF, De Leyn PR, Deneffe GJ, Lerut TE, Demedts MG. Clinica prognostic factors in surgically treated stage IIIA-N2 non-small cell lung cancer: analysis of the literature. Lung Cancer. 1998;19:3-13.

7. Betticher DC, Hsu SS, Tötsch M, Hansen E, Joss C, Von CB, Schmid RA, Pless $M$, Habicht J, Roth AD. Prognostic factors affecting long-term outcomes in patients with resected stage IIIA pN2 non-small-cell lung cancer: 5-year follow-up of a phase II study. Br J Cancer. 2006;94:1099-106.

8. PORT Meta-Analysis Trialists Group. Postoperative radiotherapy for non-small cell lung cancer. Cochrane Database Syst Rev. 2003;1.

9. Evison M, Clive A, Castle L, Powell H, Thomas R, Buttery R, Masani V, Harden S, West D, Woolhouse I. Resectable clinical N2 non-small cell lung Cancer; what is the optimal treatment strategy? An update by the British Thoracic Society lung Cancer specialist advisory group. J Thorac Oncol. 2017;12:1434-41

10. Ramón Rami-Porta HA, William D. Travis, and Valerie W. Rusch: Lung. In: AJCC cancer staging manual. edn. Edited by Mahul B. Amin M, FCAP. AMERICAN JOINTCOMMITTEEON CANCER Executive Office: Springer International Publishing AG Switzerland. 2017;431-56.

11. Asamura H, Chansky K, Crowley J, Goldstraw P, Rusch WW, Vansteenkiste JF, Watanabe H, Wu YL, Zielinski M, Ball D, Rami-Porta R. The International Association for the Study of Lung Cancer lung Cancer staging project: proposals for the revision of the $\mathrm{N}$ descriptors in the forthcoming 8th edition of the TNM classification for lung Cancer. J Thorac Oncol. 2015;10:1675-84.

12. Lin H, Chen Y, Shi A, Pandya KJ, Yu R, Yuan Y, Li J, Li H, Wang Y, Xia T, Feng L, Ma H, Geng J, Zhu G. Phase 3 randomized low-dose paclitaxel Chemoradiotherapy study for locally advanced non-small cell lung Cancer. Front Oncol. 2016;6:260.

13. Austin PC. Balance diagnostics for comparing the distribution of baseline covariates between treatment groups in propensity-score matched samples. Stat Med. 2009;28:3083-107.

14. Burdett S, Rydzewska L, Tierney J, Fisher D, Parmar M, Arriagada R, PORT Meta-analysis Trialists Group. Postoperative radiotherapy for non-small cell lung cancer. Cochrane Database Syst Rev. 2016;10;CD002142.

15. Lally BE, Zelterman D, Colasanto JM, Haffty BG, Detterbeck FC, Wilson LD. Postoperative radiotherapy for stage II or III non-small-cell lung cancer using the surveillance, epidemiology, and end results database. J Clin Oncol. 2006; 24:2998-3006

16. Corso CD, Rutter CE, Wilson LD, Kim AW, Decker RH, Husain ZA. Reevaluation of the role of postoperative radiotherapy and the impact of radiation dose for non-small-cell lung Cancer using the National Cancer Database. J Thorac Oncol. 2015;10:148-55.
17. Le Péchoux C, Dunant A, Faivre-Finn C, Thomas P-A, Pourel N, Lerouge D, Edwards J, Van Schil P, Rami-Porta R, Dansin E, Nestle U, Fadel E, Zalcman G. Postoperative radiotherapy for pathologic N2 non-small-cell lung Cancer treated with adjuvant chemotherapy: need for randomized evidence. J Clin Oncol. 2015;33:2930-1.

18. Saji H, Tsuboi M, Yoshida K, Kato Y, Nomura M, Matsubayashi J, Nagao T, Kakihana M, Usuda J, Kajiwara N, Ohira T, Ikeda N. Prognostic impact of number of resected and involved lymph nodes at complete resection on survival in non-small cell lung cancer. J Thorac Oncol. 2011;6:1865-71.

19. Wang J, Chen J, Chen X, Wang B, Li K, Bi J. Blood vessel invasion as a strong independent prognostic indicator in non-small cell lung cancer: a systematic review and meta-analysis. PLoS One. 2011;6:e28844.

20. Wang J, Wang B, Zhao W, Guo Y, Chen H, Chu H, Liang X, Bi J. Clinical significance and role of lymphatic vessel invasion as a major prognostic implication in nonsmall cell lung cancer: a meta-analysis. PLoS One. 2012;7:e52704

21. Kang DY, Lee $S$. Lymphatic vessel invasion and lymph node metastasis in patients with clinical stage I non-small cell lung cancer. Thorac Cardiovasc Surg. 2014;62:521-4.

22. Feng QF, Wang $M$, Wang $L$, Yang $Z Y$, Zhang $Y G$, Zhang DW, Yin WB. A study of postoperative radiotherapy in patients with non-small-cell lung cancer: a randomized trial. Int J Radiat Oncol Biol Phys. 2000;47:925-9.

23. Hospes R. T4 surgery in Non-Small Cell Lung Cancer. University Medical Center Groningen. 2003.

24. Patel V, Shrager JB. Which patients with stage III non-small cell lung cancer should undergo surgical resection? Oncologist. 2005;10:335-44.

25. Mayer R, Smolle-Juettner F-M, Szolar D, Stuecklschweiger GF, Quehenberger $F$, Friehs $G$, Hackl A. Postoperative radiotherapy in radically resected nonsmall cell lung Cancer. Chest. 1997;112:954-9.

26. Kwak EL, Bang YJ, Camidge DR, Shaw AT, Solomon B, Maki RG, Ou SH, Dezube BJ, Janne PA, Costa DB, Varella-Garcia M, Kim WH, Lynch TJ, Fidias P, Stubbs H, Engelman JA, Sequist LV, Tan W, Gandhi L, Mino-Kenudson M, Wei GC, Shreeve SM, Ratain MJ, Settleman J, Christensen JG, Haber DA, Wilner K, Salgia R, Shapiro Gl, Clark JW, lafrate AJ. Anaplastic lymphoma kinase inhibition in non-small-cell lung cancer. New Engl J Med. 2010;363:1693-703.

27. Pao W. New approaches to targeted therapy in lung cancer. Proc Am Thorac Soc. 2012;9:72-3.

28. Liao RG, Watanabe $H$, Meyerson M, Hammerman PS. Targeted therapy for squamous cell lung cancer. Lung Cancer Manag. 2012;1:293-300.

\section{Publisher's Note}

Springer Nature remains neutral with regard to jurisdictional claims in published maps and institutional affiliations.
Ready to submit your research? Choose BMC and benefit from:

- fast, convenient online submission

- thorough peer review by experienced researchers in your field

- rapid publication on acceptance

- support for research data, including large and complex data types

- gold Open Access which fosters wider collaboration and increased citations

- maximum visibility for your research: over $100 \mathrm{M}$ website views per year

At BMC, research is always in progress.

Learn more biomedcentral.com/submission 